\title{
Experimental and Theoretical Studies on the Creep Behavior of Bayer Red Mud
}

\author{
Baoyun Zhao $\mathbb{D D}^{1,2}$ Wei Huang, ${ }^{1,2}$ Zhile Shu, ${ }^{3}$ Mengmeng Han, ${ }^{4}$ and Yanbo Feng ${ }^{5}$ \\ ${ }^{1}$ School of Civil Engineering and Architecture, Chongqing University of Science and Technology, Chongqing 401331, China \\ ${ }^{2}$ Chongqing Key Laboratory of Energy Engineering Mechanics and Disaster Prevention and Mitigation, Chongqing 401331, China \\ ${ }^{3}$ School of Civil and Environmental Engineering, Xihua University, Chengdu 610039, China \\ ${ }^{4}$ Chongqing Test Center of Geology and Minerals, Chongqing 400042, China \\ ${ }^{5}$ School of Civil Engineering and Architecture, Chongqing University of Arts and Sciences, Chongqing 402160, China \\ Correspondence should be addressed to Baoyun Zhao; baoyun666@163.com
}

Received 11 January 2018; Accepted 29 March 2018; Published 2 May 2018

Academic Editor: Annan Zhou

Copyright ( 2018 Baoyun Zhao et al. This is an open access article distributed under the Creative Commons Attribution License, which permits unrestricted use, distribution, and reproduction in any medium, provided the original work is properly cited.

Long-term stability and safety of the Bayer red mud (BRM) disposal field is very important for the local residents' life, which necessitates the knowledge of its creep behavior. In order to investigate the creep behavior of BRM, a series of triaxial drained creep tests were conducted by using an improved triaxial creep apparatus. The results indicate that the creep behavior of BRM is significant with confining and deviatoric stresses being critical factors. The creep strain is in a nonlinear relationship with stress and time, and a larger deviator stress will lead to a larger creep strain. The main failure mechanism of BRM is plastic shear, accompanied by a significant compression and ductile dilatancy. Based on the test results, two well-established creep models, the Burgers creep model and Singh-Mitchell creep model, were used to comparatively analyze the creep behavior of the Bayer red mud under a certain stress level. Then, an improved Burgers creep damage constitutive model with the addition of a damage variable was proposed, whose parameters were also analyzed in detail. The comparison of the calculated values of the creep model and the experimental values shows that the proposed creep damage model can better describe the instant elastic deformation, attenuation creep, steady-state creep, and accelerated creep stages of the Bayer red mud.

\section{Introduction}

The Bayer red mud (BRM), also called as bauxite residue, is a hazardous solid waste generated during the Bayer alumina extraction from bauxite ore $[1,2]$. It generally exists as a highly alkaline slurry $(\mathrm{Ph} \mathrm{10-12.5)}$ that is appropriately regarded as a hazardous material [3]. As there is a great deal of industrial alkali, fluoride, heavy metals, and other potential pollutants in red mud, long-term stockpiling would not only occupy scarce land resources but also easily lead to serious pollution of the surrounding soil, air, and groundwater [4]. In the past 50 years, the wet process was used to stockpile the Bayer red mud in Guizhou Aluminum Factory red mud disposal field, which led to much unconsolidated BRM in the disposal field. At present, the production technique has been upgraded to the sintering method, more and more dried red mud was stockpiled on the unconsolidated ones directly, which much exceed the original design storage capacity. Therefore, to make disposal field stable when renewing the dry red mud, we must evaluate the long-term stability of the original Bayer red mud.

Good mechanical performance and especially creep behavior of the BRM is essential for safe and stable operation of such disposal field. Many laboratory studies investigated the creep behavior of various soils [5-7]. Yu et al. [8] performed several creep tests (lasting more than one year) to study the delayed mechanical behavior of Boom clay under the hydromechanical coupling effect. Wen and Jiang [9] discussed creep behavior of natural clayey soil with gravel at the residual state through a series of creep shear tests. Liao et al. [10] conducted a series of triaxial creep on warm frozen silts extracted from Qinghai-Tibet Plateau at a temperature 
TABLE 1: Basic physical properties of the Bayer process red mud.

\begin{tabular}{lcccccc}
\hline Wet density $\left(\mathrm{g} \cdot \mathrm{cm}^{-3}\right)$ & Water content (\%) & Specific gravity & Liquid limit (\%) & Plastic limit (\%) & Plastic index & Compressibility $\left(\mathrm{MPa}^{-1}\right)$ \\
\hline 1.75 & 44.00 & 2.72 & 48.89 & 35.77 & 13.12 & 0.20
\end{tabular}

of $-1.5^{\circ} \mathrm{C}$ under the confining pressures of $0.5,1.0$, and 2.0 MPa, respectively. Karimpour and Lade [5] performed triaxial compression tests on dense specimens of Virginia Beach sand at low and high confining pressures to study time effects that relate to grain crushing due to static fatigue or delayed fracture. The abovementioned experimental studies mostly investigated clay, sand, and frozen silts. However, concerning the study of creep mechanical behavior of the Bayer red mud, little experimental data have been reported. Therefore, studies focusing on the Bayer red mud are needed to further our understanding of its creep mechanical behavior.

Based on experimental investigations, various viscoelasticplastic models [11, 12] taking into account soil and rock microstructure and damage have been proposed. These models can be classified into three categories: empirical models, rheological models, general stress-strain-time models $[7,13]$, and damage-involved models $[14,15]$. The empirical models are mainly obtained by fitting the experimental results from creep tests; due to its relatively simple mathematical formulation and few parameters, the empirical models [16-18] are widely used to simulate the creep behavior of various soils. Rheological models usually use differential representation, visualizing the material by the elementary mechanical models composed of elastic springs, plastic sliders, and viscous dashpots $[13,19,20]$. The general stress-strain-time models are often in the incremental form and usually implemented in numerical software [21], such as the overstress model proposed by Karstunen and Yin [22] and the further extended overstress model by Yin et al. [23]. Due to its clear physical meaning and numerical convenience in programming, the general stress-strain-time model is recommended for engineering practice [21].

To clarify the creep behavior of the Bayer red mud, a series of triaxial compression creep tests were conducted on the Bayer red mud samples under different confining pressures. Based on the results, two well-established creep models, the Burgers creep model and the Singh-Mitchell equation, were used to describe the creep behavior of the Bayer red mud under a certain stress level. And then, an improved Burgers creep damage model is built to describe the creep mechanical behavior and damage evolution process of the Bayer red mud under compression. The validity of the improved model is tested by comparing the numerical simulations and test results.

\section{Test Conditions and Results}

2.1. Materials and Sample Preparation. The Bayer red mud materials were obtained from the disposal field of Guizhou aluminum factory in southwest of China. Natural Bayer red mud is a bauxite residue generated from the Bayer process (a wet process) for alumina production, which presents the color of reddish brown. X-ray diffraction was used to determine the clay minerals [24]. According to the X-ray diffraction, the Bayer red mud is comprised of cancrinite, hydrogrossular, tilleyite, calcite, and xonotlite; the main chemical constituent was $\mathrm{SiO}_{2}$ (accounting for 22.35\%), followed by $20.80 \%$ of $\mathrm{Al}_{2} \mathrm{O}_{3}, 18.51 \%$ of $\mathrm{CaO}, 8.83 \%$ of $\mathrm{Na}_{2} \mathrm{O}$, $7.73 \%$ of $\mathrm{Fe}_{2} \mathrm{O}_{3}$, and a small amount of mixture of $\mathrm{K}_{2} \mathrm{O}$, $\mathrm{MgO}, \mathrm{TiO}_{2}$, and $\mathrm{SO}_{3}$.

To avoid the nonuniformity of the undisturbed specimens, the remolded specimens were used in this study; that is, the specimens were formed into cylindrical shape, which has a height of $80 \mathrm{~mm}$ and diameter of $39.1 \mathrm{~mm}$. The average values of the index properties along with the main characteristics of the tested material are mentioned in Table 1. The Bayer red mud can be classified, according to the Unified Soil Classification System [25], as high-plasticity clays (CH).

2.2. Experimental Apparatus and Procedures. An improved strain control triaxial apparatus of TSZ-6A was used to test the creep behavior of the samples (Figure 1). The improved apparatus changes the former axial strain-controlled loading system into a weight-controlled stress loading system [26]. It also retains the confining/back pressure, pore pressure, volume change, and displacement measurement systems of the former triaxial apparatus.

After the sample was saturated under both $140 \mathrm{kPa}$ confining pressure and $110 \mathrm{kPa}$ back pressure for at least 24 hours, the triaxial creep tests were performed at an ambient temperatures of $(20 \pm 2)^{\circ} \mathrm{C}$. Based on the measured triaxial short-term compression strength, the axial deviatoric stress levels of multistep creep tests of the Bayer red mud samples were determined (Table 2), which are 16.67\%, 33.33\%, $50.00 \%, 66.67 \%, 83.33 \%$, and $100 \%$ of the maximum shortterm deviatoric stress value. Each deviatoric stress level was maintained for no less than 4500 minutes before the final failure.

2.3. Test Results and Discussions. To show the creep behavior that took place under each stress level clearly, the axial strain-time curve obtained for each stress level is plotted separately in Figure 2 (due to the limitation of the device, the volumetric creep responses of the BRM was not discussed). It is found that, under the low deviatoric stress level (less than maximum short-term deviatoric stress value), the creep curve of the Bayer red mud is composed of instant elastic deformation, attenuation creep, and steady-state creep stages. As shown in Figures 2(a)-2(c), when the deviatoric stresses are less than $591 \mathrm{kPa}, 684 \mathrm{kPa}$, and $849 \mathrm{kPa}$, respectively, only attenuation and steady creep appears in the test, while the creep phenomenon of the samples becomes significant with the increase of the deviatoric stress. It also can be obtained from Figure 2 that attenuation creep 


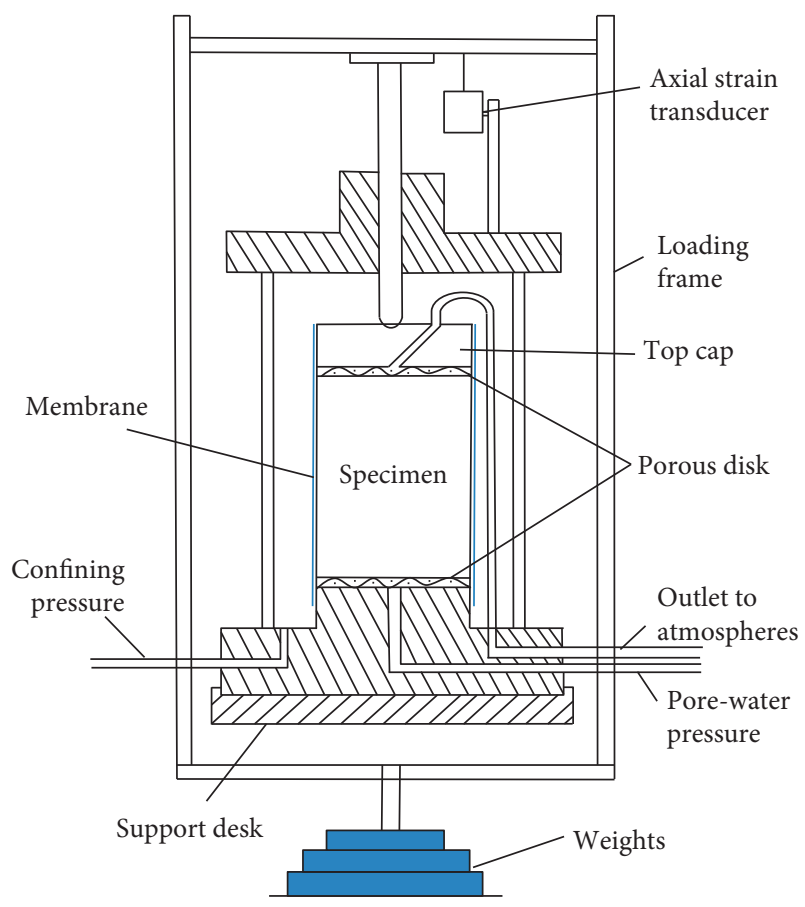

(a)

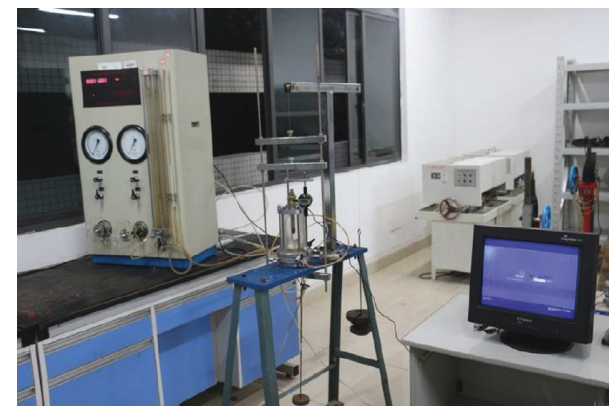

(b)

Figure 1: The weight-controlled stress loading system. (a) A schematic diagram. (b) Real picture of the apparatus.

TABLE 2: Experimental deviatoric stress levels at different confining pressures (unit: $\mathrm{kPa}$ ).

\begin{tabular}{lcccccc}
\hline Confining pressure & \multicolumn{6}{c}{ Axial deviatoric stress levels } \\
\hline 100 & 98.5 & 197.0 & 295.5 & 394.0 & 492.5 & 591.0 \\
150 & 114.1 & 228.0 & 342.0 & 456.0 & 570.0 & 684.0 \\
200 & 141.5 & 283.0 & 424.5 & 566.0 & 707.5 & 849.0 \\
\hline
\end{tabular}

occurred for a very short time and was not obvious, indicating that internal damage could not continue to occur over time under a stable lower loading level.

When the deviatoric stress reaches a certain level $(100 \%$ of the maximum short-term deviatoric stress value), the creep strain is much greater than that at previous stress levels; the accelerated creep stage appears, while instant elastic deformation and attenuation creep strain are unnoticeable. As shown in Figures 3 and 4, when the deviatoric stresses are $591 \mathrm{kPa}, 684 \mathrm{kPa}$, and $849 \mathrm{kPa}$, respectively, the original structure of the soil sample begins to destruct while

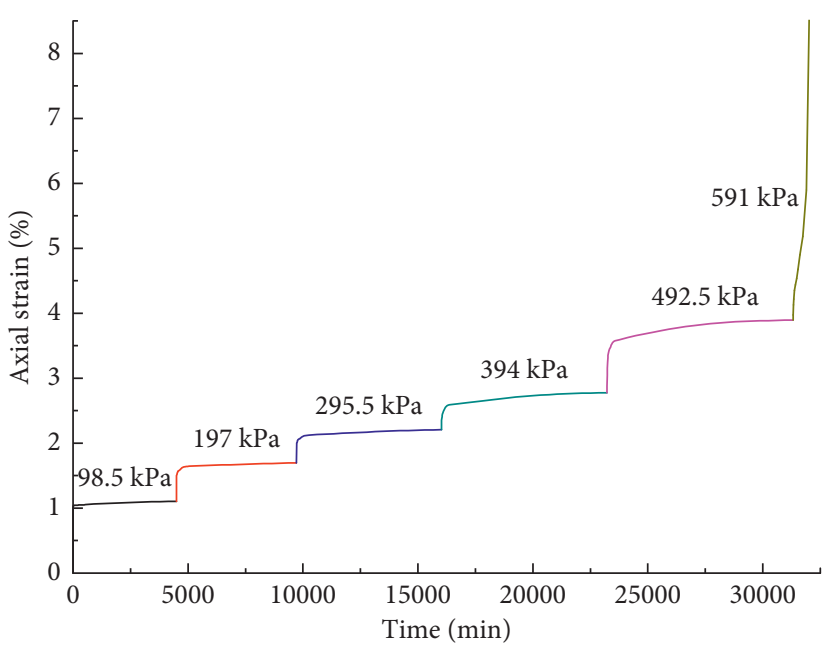

(a)

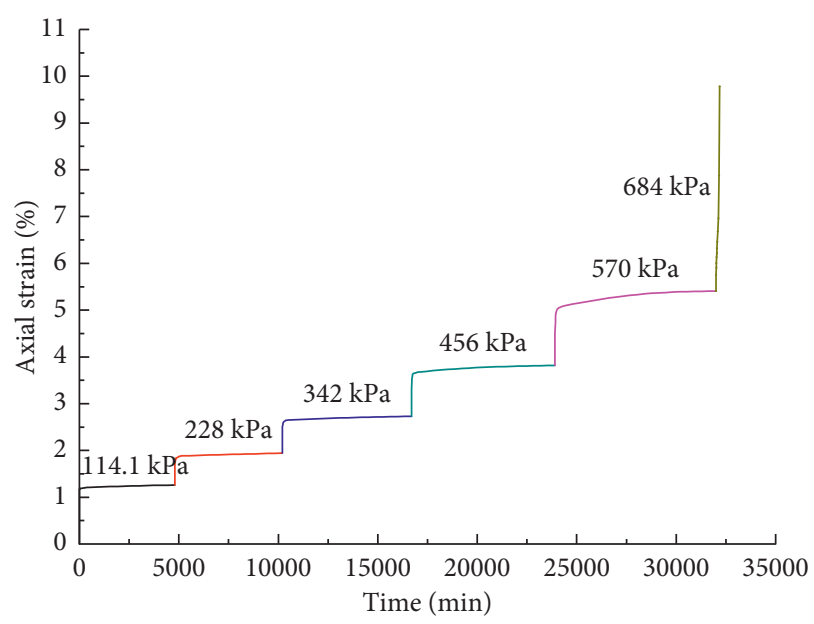

(b)

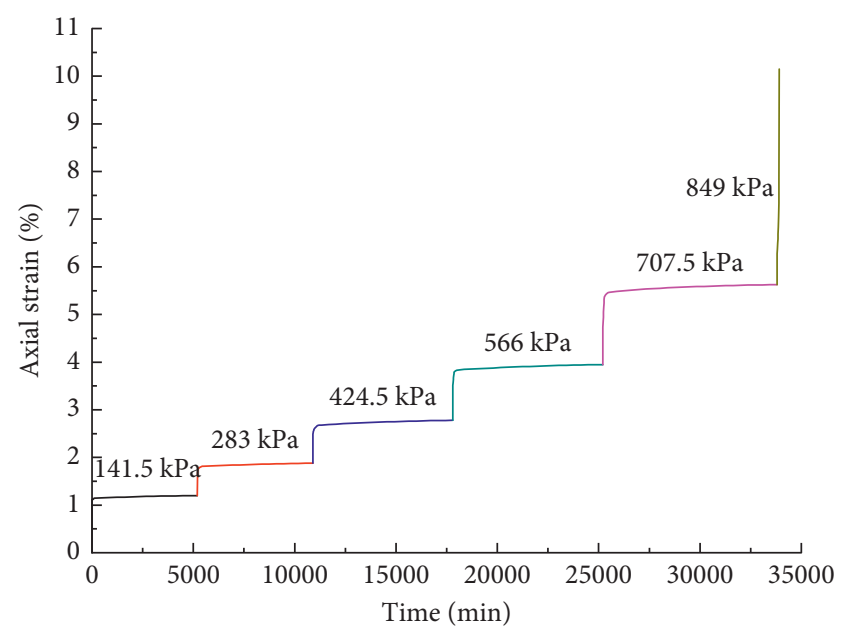

(c)

FIgURE 2: Relation between creep strain and time under different confining pressures: (a) $100 \mathrm{kPa}$, (b) $150 \mathrm{kPa}$, and (c) $200 \mathrm{kPa}$.

the displacement of the soil grains is produced that causes the creep strain of the samples to increase rapidly and fail eventually. Under the maximum deviatoric stress level, the 


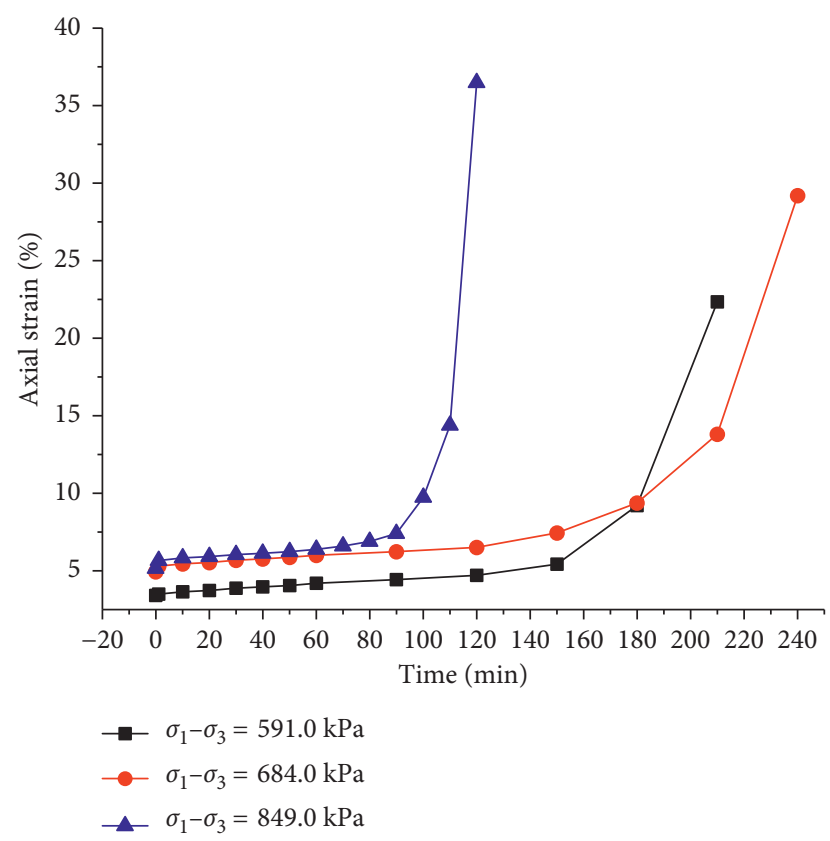

FIgURE 3: Relation between creep strain and time under different confining pressures.

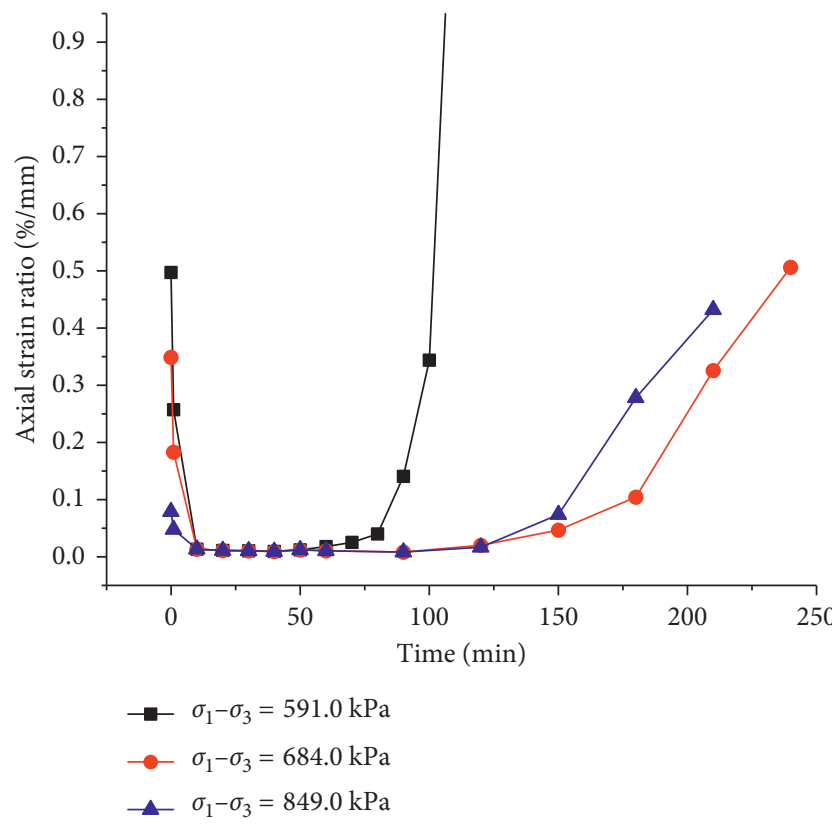

FIGURE 4: Relation between the creep strain ratio and time under different confining pressures.

process for each stress level lasts only for 110, 210, and 210 minutes. Figure 5 shows a schematic view of the red mud sample after failure under the deviatoric stress of $591 \mathrm{kPa}$ and the confining pressure of $100 \mathrm{kPa}$; the main feature associated with the failure is the high axial plastic strain due to the accumulation of the former deviatoric stress level's damage effects, and no brittle damage is observed in the samples. These results indicated that damage had begun to occur in weak local areas of the soil sample, causing increasing

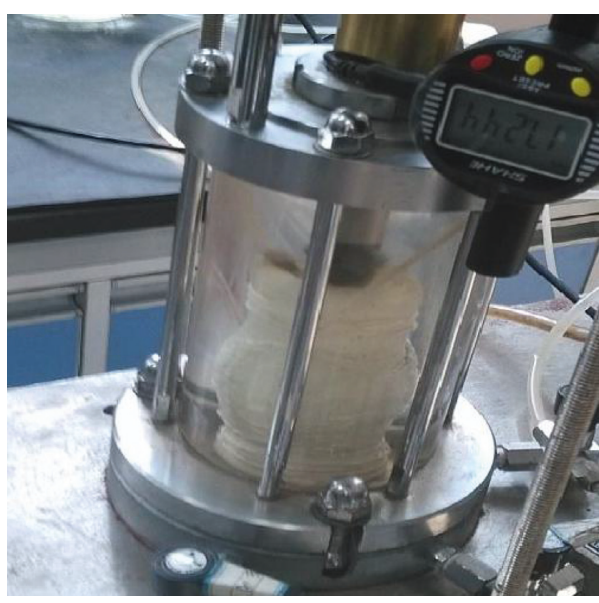

FIGURE 5: Failure mode of the specimen tested under the deviatoric stress of $590 \mathrm{kPa}$ and the confining pressure of $100 \mathrm{kPa}$.

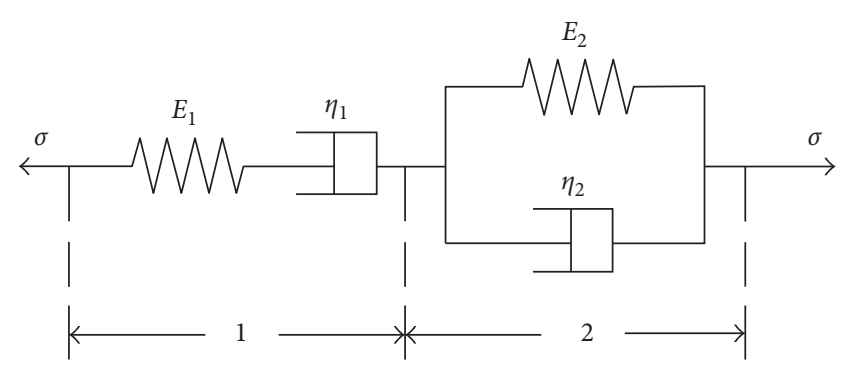

Figure 6: The Burgers creep model.

damage and time required for internal stress nonlinear adjustment to an equilibrium state with increased load.

\section{Comparative Analysis of Two Creep Constitutive Models}

The creep curves in Figure 2 show that the Bayer red mud sample experiences an attenuation creep stage and a steady creep stage when the stress level was less than a certain threshold and no obvious damage occurred over time.

According to the behavior shown by these curves, two well-established creep models, the Burgers creep model and the Singh-Mitchell equation, were used to describe the creep behavior of the Bayer red mud.

The Burgers creep model $[27,28]$ is made up of the Kelvin and Maxwell models in series as shown in Figure 6.

The creep equation of the Burgers creep model is

$$
\varepsilon=\frac{\sigma}{E_{1}}+\frac{\sigma}{\eta_{1}} t+\frac{\sigma}{E_{2}}\left(1-e^{-\left(E_{2} / \eta_{2}\right) t}\right),
$$

where $\sigma$ is the deviatoric stress; $E_{1}$ and $\eta_{1}$ are the elastic modulus and viscosity coefficient of the Maxwell body; and $E_{2}$ and $\eta_{2}$ are the elastic modulus and viscosity coefficient of the Kelvin body, respectively.

The Singh-Mitchell model is an empirical equation with three parameters [16]. The creep equation of the SinghMitchell model is given as [27] 


$$
\begin{aligned}
\varepsilon & =B_{1} e^{\beta D}\left(\frac{t}{t_{1}}\right)^{\lambda}, \\
B_{1} & =\frac{A_{1} t_{1}}{1-m}, \\
\beta & =\alpha, \\
\lambda & =1-m,
\end{aligned}
$$

where $\lambda$ is the slope of $\ln \varepsilon$ against $\ln t$ at any fixed value of $D, \beta$ is the slope of $\ln t$ against $D$, at any fixed time, and $B_{1}$ is the intercept of $\ln \varepsilon$ against $D$ at $t=t_{1}$.

The data measured under multistep loading in the test are processed using the Boltzmann superposition [29]. Based on the quasi-Newton search method [30] by the software of Origin 8.5, the Burgers model and the Singh-Mitchell model are used to fit the creep data to obtain the creep parameters. The comparison among the Burgers model's predictions of creep curves, the Singh-Mitchell model's predictions of creep curves, and the experimental creep results under different confining pressures is shown in Figure 7 . The relevant parameters of the Burgers creep model and the Singh-Mitchell model identified from the data processing are shown in Tables 3 and 4 . It is observed that both the models can capture the creep behavior of the Bayer red mud, but the Burgers model results are consistent with the experimental data, and the model can better describe the typical creep behavior under the stress less than a certain threshold.

\section{Damage Evolution Equation and Improved Burgers Creep Damage Model}

4.1. Damage Evolution. According to the former test results, it can be obtained that if the applied load is much higher, the structure of the soil sample begins to destruct and the creep strain of the samples increases rapidly in the accelerated creep stage and fails eventually. Kachanov [31] suggested that this increase in the strain rate can be described by the introduction of a damage variable into the constitutive equation. The concept of an effective stress proposed by Kachanov [32] has been used to formulate constitutive equations for damaged materials [33]. From the test results, we assume that the damage evolution begins at the steady creep stage. So, the evolution equation of the damage variable can be expressed as [10]

$$
D=1-\exp \left(-\frac{\varepsilon-\varepsilon_{0}}{\varepsilon_{0}}\right),
$$

where $\varepsilon$ and $D$ are creep strain and damage factor, respectively; while $\varepsilon_{0}$ is the damage initial strain, which can be obtained at the starting point of the steady creep stage.

According to the whole creep curves (Figure 3), an exponential equation (4) was used to describe the strain of $\varepsilon-\varepsilon_{0}$. The fitting test results are shown in Figure 8 when $\varepsilon_{0}$ are $4.13 \%, 5.91 \%$, and $6.28 \%$, respectively. And the squares of

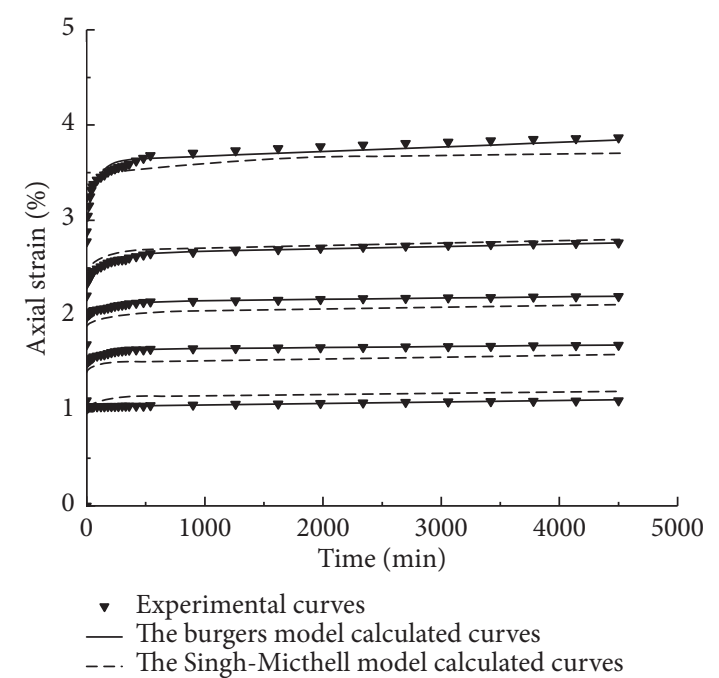

(a)

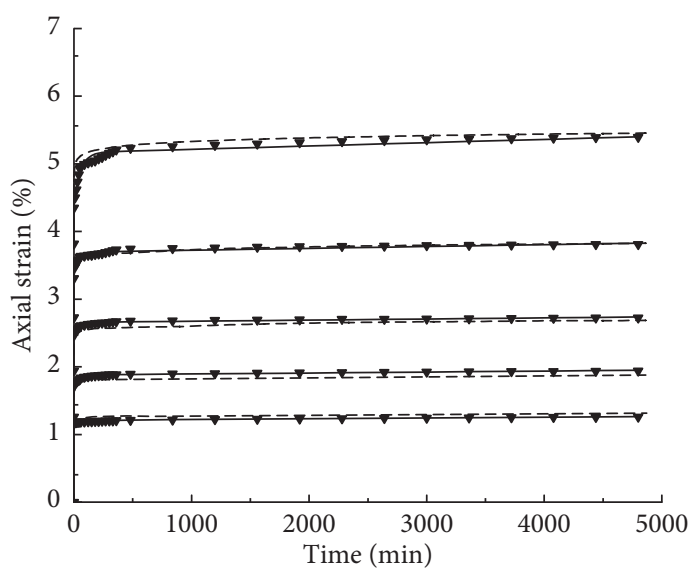

- Experimental curves

- The burgers model calculated curves

- - The Singh-Mitchell model calculated curves

(b)

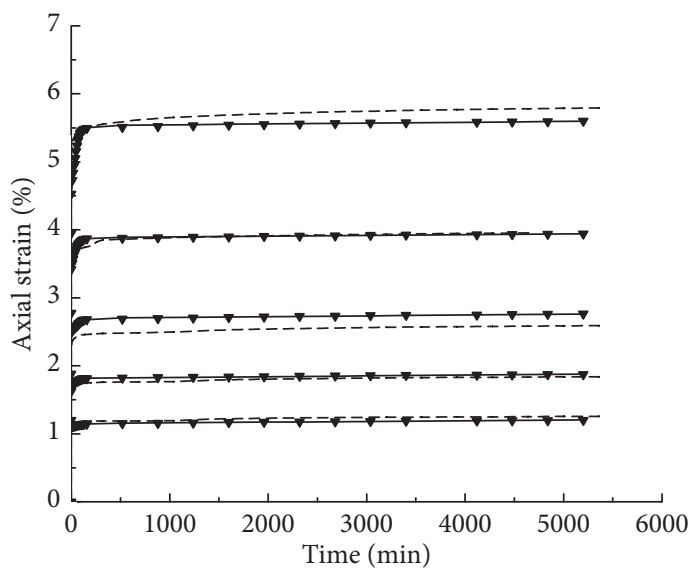

- Experimental curves

- The burgers model calculated curves

- - The Singh-Mitchell model calculated curves

(c)

FIgURE 7: Comparison between the Burgers mode predicted creep curves and the experimental curves. Confining pressure: (a) $100 \mathrm{kPa}$, (b) $150 \mathrm{kPa}$, and (c) $200 \mathrm{kPa}$. 
TABLE 3: Burgers model creep parameters of the BRM under different confining pressures.

\begin{tabular}{|c|c|c|c|c|c|c|}
\hline \multirow{2}{*}{ Confining pressure $(\mathrm{kPa})$} & \multirow{2}{*}{ Deviatoric stress $(\mathrm{kPa})$} & \multicolumn{4}{|c|}{ Burgers model parameters } & \multirow{2}{*}{$R^{2}$} \\
\hline & & $E_{1}(\mathrm{kPa})$ & $\eta_{1}(\mathrm{kPa} \cdot \mathrm{min})$ & $E_{2}(\mathrm{kPa})$ & $\eta_{2}(\mathrm{kPa} \cdot \mathrm{min})$ & \\
\hline \multirow{5}{*}{100} & 98.5 & 128.17 & 13966524.90 & 3020.84 & 13966524.9 & 1.000 \\
\hline & 197 & 173.71 & 24214292.80 & 1509.58 & 52422.20 & 0.995 \\
\hline & 295.5 & 171.01 & 33992245.50 & 1973.32 & 140306.04 & 0.991 \\
\hline & 394 & 166.11 & 50861180.30 & 1191.11 & 54682.70 & 0.991 \\
\hline & 492.5 & 157.47 & 57960664.70 & 680.23 & 31802.25 & 0.962 \\
\hline \multirow{5}{*}{150} & 114.1 & 96.86 & 10789254.90 & 3369.48 & 872176.59 & 0.993 \\
\hline & 228 & 132.50 & 15930262.60 & 1432.39 & 77164.05 & 0.992 \\
\hline & 342 & 138.43 & 20909142.90 & 1830.65 & 3036.11 & 0.982 \\
\hline & 456 & 136.74 & 16576719.60 & 1263.86 & 40147.25 & 0.951 \\
\hline & 570 & 130.22 & 11547983.90 & 724.10 & 38893.11 & 0.967 \\
\hline \multirow{5}{*}{200} & 141.5 & 128.17 & 13966524.90 & 3020.84 & 234325.89 & 0.995 \\
\hline & 283 & 173.71 & 24214292.80 & 1509.58 & 52422.20 & 0.992 \\
\hline & 424.5 & 171.01 & 33992245.50 & 1973.32 & 140306.04 & 0.993 \\
\hline & 566 & 166.11 & 50861180.30 & 1191.11 & 54682.70 & 0.999 \\
\hline & 707.5 & 157.47 & 57960664.70 & 680.23 & 31802.25 & 0.996 \\
\hline
\end{tabular}

TABLE 4: Singh-Mitchell model parameters of the BRM under different confining pressures.

\begin{tabular}{|c|c|c|c|c|c|}
\hline \multirow{2}{*}{ Confining pressure $(\mathrm{kPa})$} & \multirow{2}{*}{ Deviatoric Stress $(\mathrm{kPa})$} & \multicolumn{4}{|c|}{ Singh-Mitchell model parameters } \\
\hline & & $D$ & $\beta$ & $B_{1}$ & Average $\lambda$ \\
\hline \multirow{5}{*}{100} & 98.500 & 0.166 & \multirow{5}{*}{1.690} & \multirow{5}{*}{0.840} & \multirow{5}{*}{0.0191} \\
\hline & 197.000 & 0.332 & & & \\
\hline & 295.500 & 0.497 & & & \\
\hline & 394.000 & 0.663 & & & \\
\hline & 492.500 & 0.829 & & & \\
\hline \multirow{5}{*}{150} & 114.100 & 0.166 & \multirow{5}{*}{2.121} & \multirow{5}{*}{0.873} & \multirow{5}{*}{0.014} \\
\hline & 228.000 & 0.334 & & & \\
\hline & 342.000 & 0.501 & & & \\
\hline & 456.000 & 0.667 & & & \\
\hline & 570.000 & 0.834 & & & \\
\hline \multirow{5}{*}{200} & 141.500 & 0.167 & \multirow{5}{*}{2.286} & \multirow{5}{*}{0.803} & \multirow{5}{*}{0.015} \\
\hline & 283.000 & 0.334 & & & \\
\hline & 424.500 & 0.501 & & & \\
\hline & 566.000 & 0.668 & & & \\
\hline & 707.500 & 0.835 & & & \\
\hline
\end{tabular}

the fitting correlation coefficient $\left(R^{2}\right)$ are $0.995,0.983$, and 0.946 , respectively, indicating that the exponential equation (4) can well describe the steady creep and accelerated stages of the Bayer red mud samples.

$$
\varepsilon-\varepsilon_{0}=A t^{\beta} .
$$

By substituting (4) into (3), we can construct the soil damage evolution constitutive model:

$$
D=1-\exp \left(-\alpha \frac{t^{\beta}}{t_{0}^{\beta}}\right),
$$

where $\alpha$ and $\beta$ are the parameters controlling the damage evolution with time, which are related to the stress levels. $t$ is the creep time and $t_{0}$ is the unit time, which value is 1 . The relationship between the damage evolution and creep time, obtained by fitting the test results, is shown in Figure 9; the parameters of the damage constitutive model are listed in Table 5 .
4.2. Improved Burgers Creep Damage Model. The viscous coefficient will increase with the effect of low stress and decrease when the stress that exceeds the long-term ultimate strength [34]. According to the above test results, a new nonlinear viscoplasticity model was presented based on the creep damage model represented by (5). Also, in series with the Burgers creep model, a new improved Burgers creep damage model (Figure 10) was proposed, which can accurately describe the properties of the BRM during the instantaneous creep, decay creep, steady creep, and accelerating creep stages, to explain the evolution law of the damage characteristics over time.

If a series connection is made for each creep body in Figure 10, then

$$
\varepsilon=\varepsilon_{1}+\varepsilon_{2}+\varepsilon_{3}
$$

Based on (1-6), the creep equation of the improved Burgers damage model 1 under the effect of constant compression stress is 


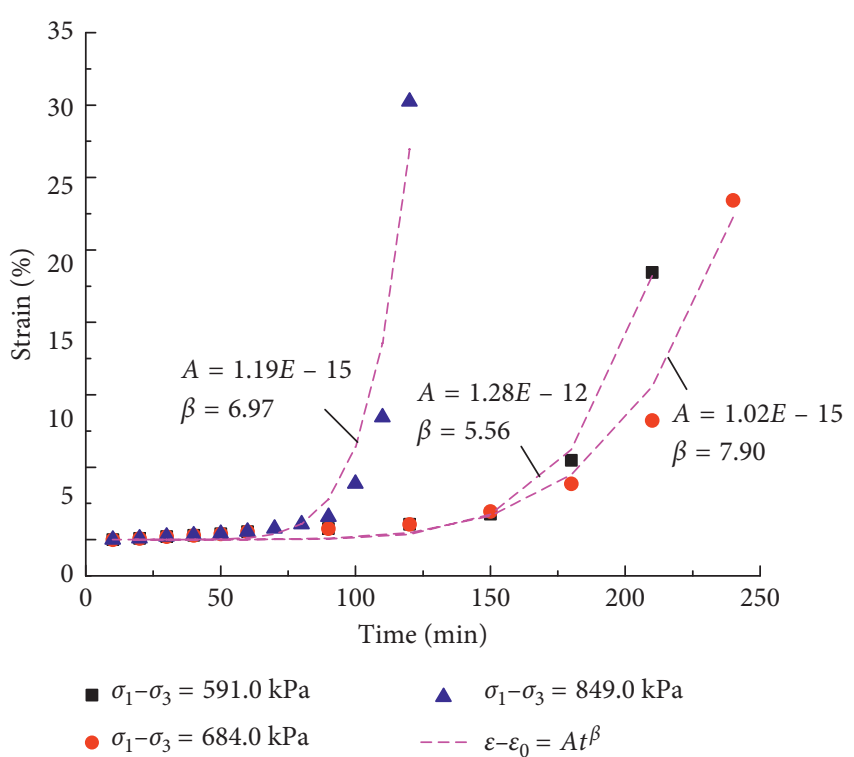

FIgURE 8: Relationship between the exponential equation fitting curves and test curves.

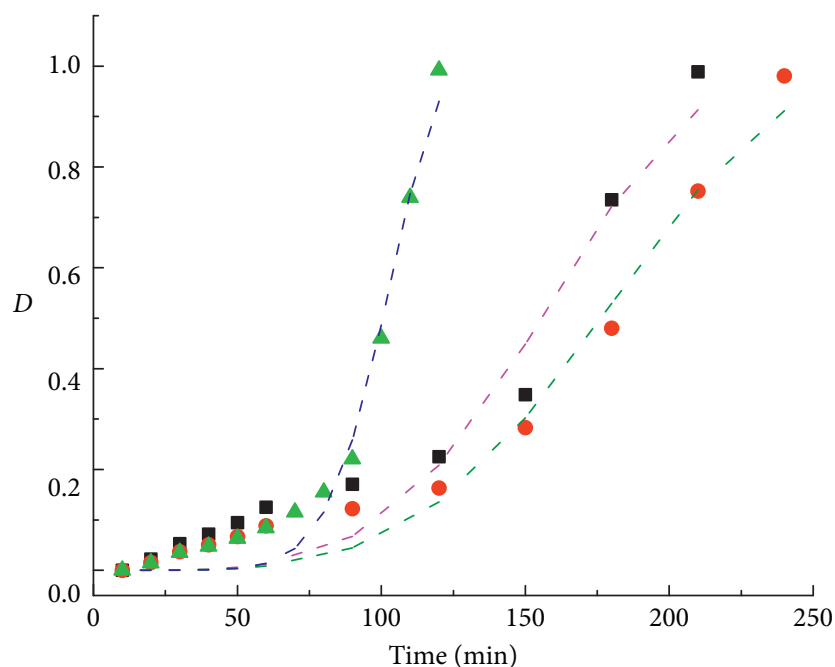

- Test data: $\sigma_{1}-\sigma_{3}=591.0 \mathrm{kPa} \triangle$ Test data: $\sigma_{1}-\sigma_{3}=849.0 \mathrm{kPa}$

- Test data: $\sigma_{1}-\sigma_{3}=684.0 \mathrm{kPa}---\quad D=1-\exp \left(-\alpha t^{\beta}\right)$

Figure 9: Damage evolution under different stress levels.
TABle 5: The parameters of the damage constitutive model.

\begin{tabular}{lcccc}
\hline $\begin{array}{l}\text { Confining pressure } \\
(\mathrm{kPa})\end{array}$ & $\begin{array}{c}\text { Deviatoric stress } \\
(\mathrm{kPa})\end{array}$ & $\alpha$ & $\beta$ & $R^{2}$ \\
\hline 100 & 591 & $4.43 E-10$ & 4.19 & 0.97 \\
150 & 684 & $5.35 E-10$ & 4.06 & 0.98 \\
200 & 849 & $4.16 E-16$ & 7.60 & 0.99 \\
\hline
\end{tabular}

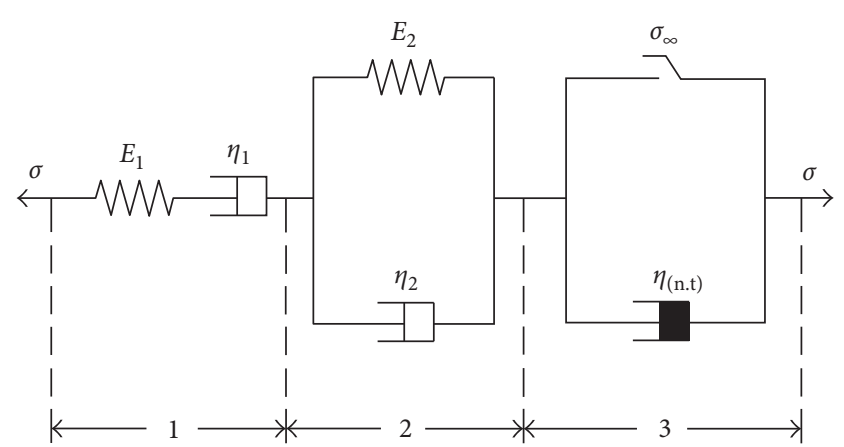

Figure 10: Illustration of the improved Burgers damage model.

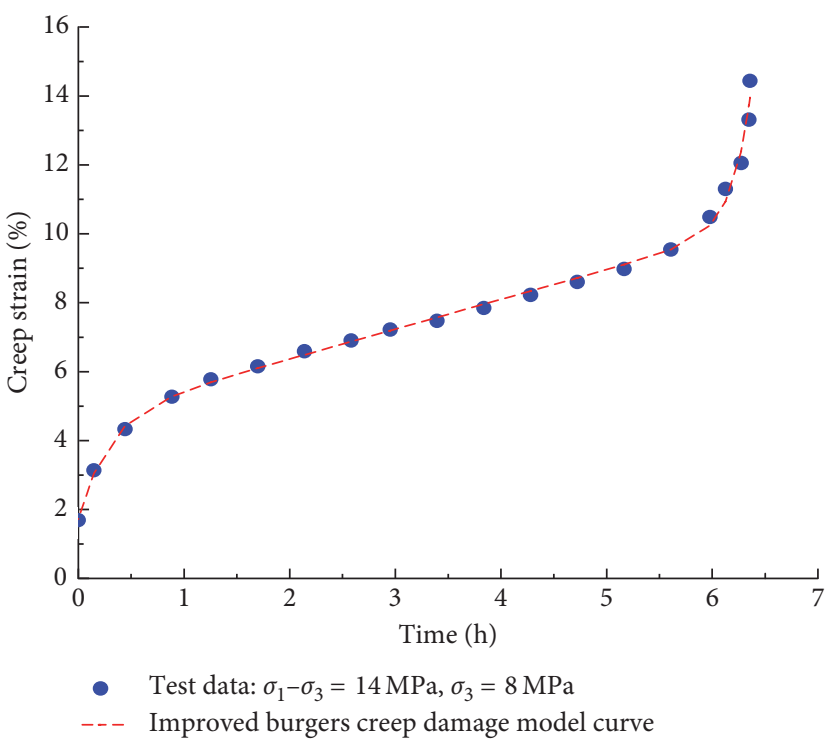

Figure 11: Comparison between the improved Burgers creep damage model curve with the test result from Li et al. [35].

$$
\begin{array}{ll}
\varepsilon=\frac{\sigma_{0}}{E_{1}}+\frac{\sigma_{0}}{\eta_{1}} t+\frac{\sigma_{0}}{E_{2}}\left(1-\exp \left(-\frac{E_{2}}{\eta_{2}} t\right)\right) & \left(\sigma<\sigma_{\infty}\right) \\
\varepsilon=\frac{\sigma_{0}}{E_{1}}+\frac{\sigma_{0}}{\eta_{1}} t+\frac{\sigma_{0}}{E_{2}}\left(1-\exp \left(-\frac{E_{2}}{\eta_{2}} t\right)\right)+\frac{\sigma_{0}-\sigma_{\infty}}{\eta_{3}(1-D)} t \quad\left(\sigma \geq \sigma_{\infty}\right),
\end{array}
$$

where $\sigma_{\infty}$ is the long-term strength which is the threshold of the damage and $\eta_{3}$ is the original viscosity coefficient.

Test data of artificially frozen soil that is reproduced from [35] was used to validate and analyze the applicability of the improved Burgers damage model, as shown in
Figure 11. The creep parameters of this soil are shown in Table 6. It can be seen clearly that the creep experimental results of the Bayer red mud agree very well with the numerical prediction using the improved Burgers creep damage model, and square of the correlation coefficient $\left(R^{2}\right)$ 
TABLE 6: Improved Burgers damage creep model parameters of artificially frozen soil [35].

\begin{tabular}{lccccccc}
\hline$E_{1}(\mathrm{kPa})$ & $\eta_{1}(\mathrm{kPa} \cdot \min )$ & $E_{2}(\mathrm{kPa})$ & $\eta_{2}(\mathrm{kPa} \cdot \min )$ & $\eta_{3}(\mathrm{kPa} \cdot \min )$ & $\alpha$ & $\beta$ & $R^{2}$ \\
\hline 376.26 & 752.45 & 205.89 & 57.49 & $3.27 E+11$ & 0.63 & 1.86 & 0.996 \\
\hline
\end{tabular}

TABLE 7: Improved Burgers damage creep model parameters under different confining pressures.

\begin{tabular}{lcccccc}
\hline$E_{1}(\mathrm{kPa})$ & $\eta_{1}(\mathrm{kPa} \cdot \mathrm{min})$ & $E_{2}(\mathrm{kPa})$ & $\eta_{2}(\mathrm{kPa} \cdot \mathrm{min})$ & $\eta_{3}(\mathrm{kPa} \cdot \min )$ & $\alpha$ & $\beta$ \\
\hline 15168.31 & $7.33 E+11$ & 135781.55 & 0.74 & $1.30 E+11$ & 0.76 & 0.52 \\
12649.08 & $6.27 E+06$ & 187336.83 & 2.97 & $1.03 E+15$ & 2.47 & 0.39 \\
15089.88 & $1.58 E+21$ & 81472.33 & 0.22 & $3.06 E+14$ & 1.01 & 0.995 \\
\hline
\end{tabular}

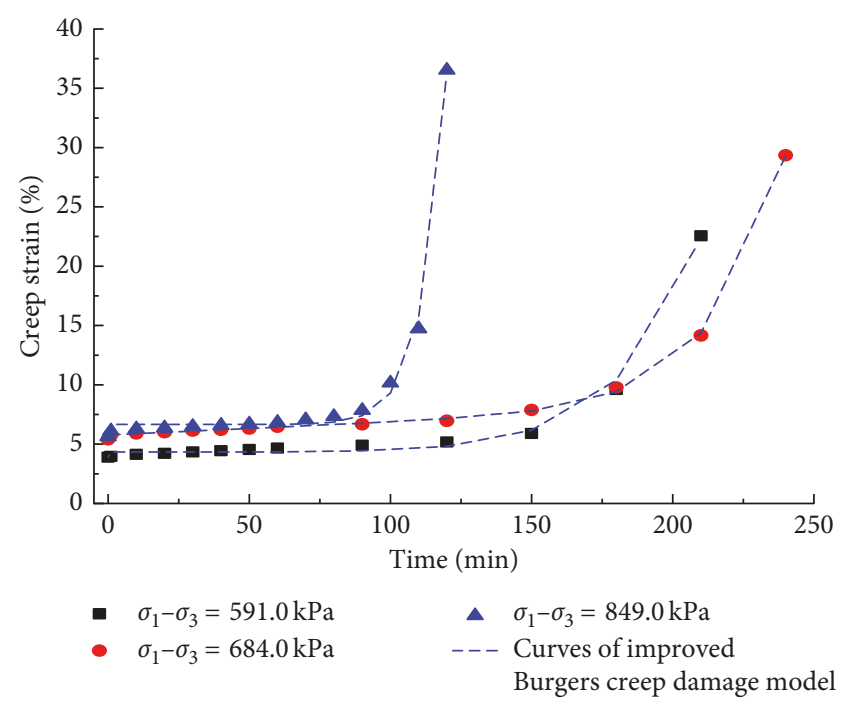

Figure 12: Comparison between the improved Burgers creep model's prediction of creep curves and the tested results.

is 0.996, indicating that the improved Burgers creep damage model has good applicability.

\subsection{Parameter Identification of Improved Burgers Creep} Model. In order to determine creep mechanical parameters of the improved Burgers creep model at different deviatoric stresses, an iteration procedure was used based on the quasiNewton search method [30]. The relevant parameters of the improved Burgers creep damage model were identified from data processing, as shown in Table 7 , and the calculated results of the creep curves and the tested ones are shown in Figure 12. From Figure 12, it is found that the calculated results of the proposed model are in good agreement with the tested results under these three deviatoric stress $(591 \mathrm{kPa}$, $684 \mathrm{kPa}$, and $849 \mathrm{kPa}$ ). The correlation coefficient squares $\left(R^{2}\right)$ of the three curves are $0.995,0.996$, and 0.996 , respectively, indicating that the prediction precision of the proposed model here is high in the simulating properties of the Bayer red mud.

\section{Conclusions}

The aim of this research is to lay a foundation for the evaluation and design processes in the Bayer red mud in the Guizhou Aluminum Factory red mud disposal field. A series of triaxial drained creep tests were conducted under different confining and deviatoric stresses. The test results indicate that the Bayer red mud has two creep stages under lower deviatoric stresses, namely, the attenuation creep stage and the steady creep stage; while in high deviatoric stress level, the accelerated creep stage with less instant elastic deformation and attenuation creep strain appears. The main failure mechanism of the Bayer red mud is plastic shear, accompanied by a significant compression and ductile dilatancy.

Based on the tested results, the creep parameters of the Burgers creep model and Singh-Mitchell creep model were determined through the curve fitting of the measured data. The results demonstrate a high precision of the Burgers creep model in prediction of the creep curve under certain deviatoric stress level, compared with the Singh-Mitchell creep model.

A new damage evolution constitutive equation of the Bayer red mud was constructed according to the creep strain of steady creep and accelerating creep stages and combined with the Burgers creep model, and a new improved Burgers creep damage model was proposed, which parameters were also analyzed in detail. The improved Burgers creep damage model which has been verified by the conformity of the result of the experiment illustrates that the model can accurately describe the properties of the BRM during the instant elastic strain, attenuation creep, steady creep, and accelerating creep stages.

\section{Conflicts of Interest}

The authors declare that there are no conflicts of interest regarding the publication of this paper.

\section{Acknowledgments}

This study was partially supported by the National Natural Science Foundation of China (Grant no. 41302223), Science and Technology Plan Projects of Chongqing Administration of Land, Resources and Housing (KJ-2015047), Chongqing No. 3 Colleges and Universities Youth Backbone Teachers Funding Plans and Chongqing Research Program of Basic Research and Frontier Technology (cstc2016jcyjA0074, cstc2016jcyjA0933, and cstc2015jcyjA90012), and Scientific and Technological Research Program of Chongqing $\mathrm{Mu}-$ nicipal Education Commission (KJ1713327 and KJ1600532). The authors also thank Professor Yang Mijia, Department of 
Civil and Environmental Engineering, North Dakota State University, for his valuable suggestions and English improvement of this manuscript.

\section{References}

[1] A. R. Hind, S. K. Bhargava, and S. C. Grocott, "The surface chemistry of Bayer process solids: a reviews," Colloids and Surfaces A: Physicochemical and Engineering Aspects, vol. 146, no. 1-3, pp. 359-374, 1999.

[2] Y. F. Huang, G. H. Han, J. T. Liu, and W. J. Wang, "A facile disposal of Bayer red mud based on selective flocculation desliming with organic humics," Journal of Hazardous Materials, vol. 301, pp. 46-55, 2016.

[3] X. F. Zhu, T. A. Zhang, Y. X. Wang, G. Z. Lü, and W. G. Zhang, "Recovery of alkali and alumina from Bayer red mud by the calcification-carbonation method," International Journal of Minerals, Metallurgy and Materials, vol. 23, no. 3, pp. 257-268, 2016.

[4] P. Wang and D. Y. Liu, "Physical and chemical properties of sintering red mud and Bayer red mud and the implications for beneficial utilization," Materials, vol. 5, no. 10, pp. 1800-1810, 2012.

[5] H. Karimpour and P. V. Lade, "Creep behavior in Virginia Beach sand," Canadian Geotechnical Journal, vol. 50, no. 11, pp. 1159-1178, 2013.

[6] Y. B. Zhu and H. M. Yu, "Unsaturated creep behaviors of weak intercalated soils in soft rock of Badong formation," Journal of Mountain Science, vol. 12, no. 6, pp. 1460-1470, 2015.

[7] X. L. Lai, S. M. Wang, W. M. Ye, and Y. J. Cui, "Experimental investigation on the creep behavior of an unsaturated clay," Canadian Geotechnical Journal, vol. 51, no. 6, pp. 621-628, 2014.

[8] H. D. Yu, W. Z. Chen, Z. Gong et al., "Creep behavior of boom clay," International Journal of Rock Mechanics and Mining Sciences, vol. 76, pp. 256-264, 2015.

[9] B. P. Wen and X. Z. Jiang, "Effect of gravel content on creep behavior of clayey soil at residual state: implication for its role in slow-moving landslides," Landslides, vol. 14, no. 2, pp. 559-576, 2017.

[10] M. K. Liao, Y. M. Lai, E. L. Liu, and X. S. Wan, "A fractional order creep constitutive model of warm frozen silt," Acta Geotechnica, vol. 12, no. 2, pp. 377-389, 2017.

[11] H. Zhou, Y. Jia, and J. Shao, "A unified elastic-plastic and viscoplastic damage model for quasi-brittle rocks," International Journal of Rock Mechanics and Mining Sciences, vol. 45, no. 8, pp. 1237-1251, 2008.

[12] T. Bui, H. Wong, F. Deleruyelle, and A. Zhou, "Constitutive modelling of the time-dependent behaviour of partially saturated rocks," Computers and Geotechnics, vol. 78, pp. 123133, 2016.

[13] D. K. Kim, "Comparisons of overstress theory with an empirical model in creep prediction for cohesive soils," KSCE Journal of Civil Engineering, vol. 9, no. 6, pp. 489-494, 2005.

[14] V. De Gennaro and J. A. Pereira, "Viscoplastic constitutive model for unsaturated geomaterials," Computers and Geotechnics, vol. 54, pp. 143-151, 2013.

[15] T. A. Bui, H. Wong, F. Deleruyelle, L. Z. Xie, and D. T. Tran, "A thermodynamically consistent model accounting for viscoplastic creep and anisotropic damage in unsaturated rocks," International Journal of Solids and Structures, vol. 117, pp. 26-38, 2017.
[16] A. Singh and J. K. Mitchell, "General stress-strain-time function for soils," Journal of Soil Mechanics and Found Engineering Division, vol. 94, no. 1, pp. 21-46, 1968.

[17] G. Mesri, E. Rebres-Cordero, D. R. Shields, and A. Castro, "Shear stress strain-time behavior of clays," Géotechnique, vol. 31, no. 4, pp. 537-552, 1981.

[18] J. H. Yin, "Non-linear creep of soils in oedometer tests," Geotechnique, vol. 49, no. 5, pp. 699-707, 1999.

[19] J. K. Mitchell, Fundamentals of Soil Behavior, Wiley, New York, NY, USA, 2nd edition, 1993.

[20] H. M. Gao, Y. M. Chen, H. L. Liu, J. Y. Liu, and J. Chu, "Creep behavior of EPS composite soil," Science China Technological Sciences, vol. 55, no. 11, pp. 3070-3080, 2012.

[21] S. H. Wang, J. L. Qi, Z. Y. Yin, J. M. Zhang, and W. Ma, “A simple rheological element based creep model for frozen soils," Cold Regions Science and Technology, vol. 106-107, pp. 47-54, 2014.

[22] M. Karstunen and Z. Y. Yin, "Modelling time-dependent behaviour of Murro test embankment," Geotechnique, vol. 60, no. 10, pp. 735-749, 2010.

[23] Z. Y. Yin, M. Karstunen, C. S. Chang, M. Koskinen, and M. Lojander, "Modeling time-dependent behavior of soft sensitive clay," Journal of Geotechnical and Geoenvironmental Engineering, vol. 137, no. 11, pp. 103-1113, 2011.

[24] M. M. Han, Study on Creep Characteristics of Red Mud from Bayer Process, M.S. thesis, Chongqing University, Chongqing, China, 2015.

[25] ASTM, Standard Practice for Classification of Soils for Engineering Purpose. Annual Book of ASTM Standards, ASTM International D4767-11, West Conshohocken, PA, USA, 2011.

[26] W. Huang, D. Y. Liu, B. Y. Zhao, Y. B. Feng, and Y. C. Xia, "Study on the rheological properties and constitutive model of Shenzhen mucky soft soil," Journal of Engineering Science and Technology, vol. 7, pp. 55-61, 2014.

[27] M. J. Sun, H. M. Tang, M. Y. Wang, Z. G. Shan, and X. L. Hu, "Creep behavior of slip zone soil of the Majiagou landslide in the Three Gorges area," Environmental Earth Sciences, vol. 75, no. 16, p. 1199, 2016.

[28] W. B. Ma, Q. H. Rao, P. Li, S. C. Guo, and K. Feng, "Shear creep parameters of simulative soil for deep-sea sediment," Journal of Central South University, vol. 21, no. 12, pp. 4682-4689, 2014.

[29] T. K. Tan, Z. O. Shi, Z. H. Yu, and W. X. Yang, "Dilatancy, creep and relaxation of brittle rocks measured with the 8000 $\mathrm{kN}$ multipurpose triaxial apparatus," Physics of the Earth and Planetary Interiors, vol. 55, no. 3-4, pp. 335-352, 1989.

[30] Y. Zhang, W. Y. Xu, J. F. Shao, H. B. Zhao, and W. Wang, "Experimental investigation of creep behavior of clastic rock in Xiangjiaba Hydropower Project," Water Science and Engineering, vol. 8, no. 1, pp. 55-62, 2015.

[31] L. M. Kachanov, The Theory of Creep: Part I, National Lending Library for Science and Technology, Boston, MA, USA, 1967.

[32] L. M. Kachanov, "Rupture time under creep conditions," International Journal of Fracture, vol. 97, pp. 11-18, 1999.

[33] J. Lemaitre and J. L. Chaboche, Mechanics of Solid Materials, Cambridge University Press, New York, NY, USA, 1990.

[34] P. Cao, Y. D. Wen, Y. X. Wang, H. P. Yuan, and B. X. Yuan, "Study on nonlinear damage creep constitutive model for high-stress soft rock," Environmental Earth Sciences, vol. 75, no. 10, p. 900, 2016.

[35] D. W. Li, J. H. Fan, and R. H. Wang, "Research on viscoelastic-plastic creep model of artificially frozen soil under high confining pressures," Cold Regions Science and Technology, vol. 65, no. 2, pp. 219-225, 2011. 


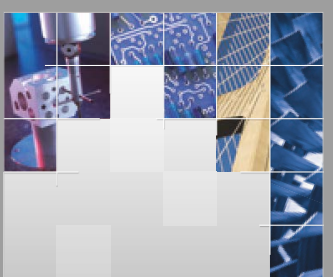

\section{Enfincering}
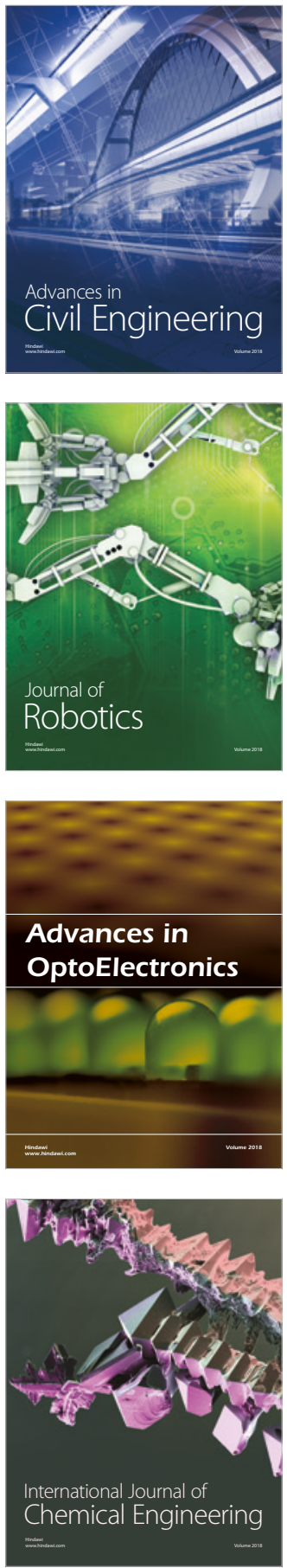

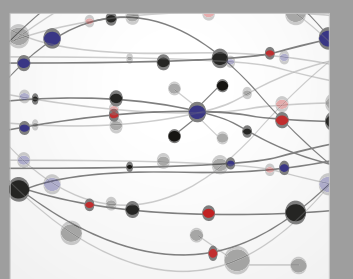

\section{Rotating \\ Machinery}

The Scientific World Journal

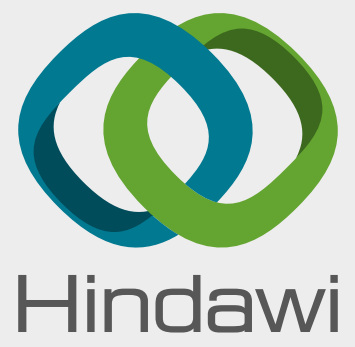

Submit your manuscripts at

www.hindawi.com
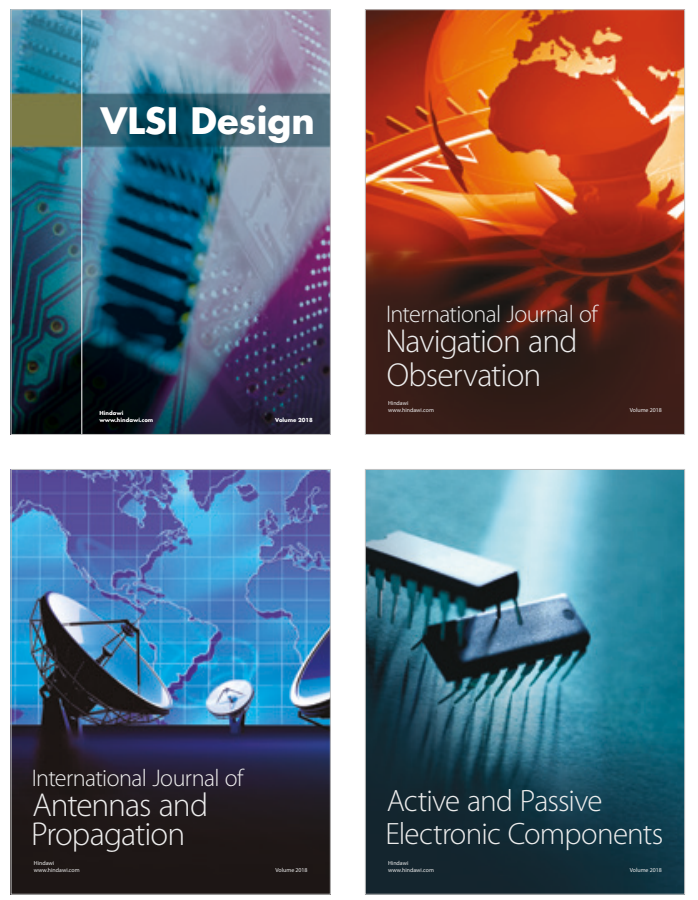
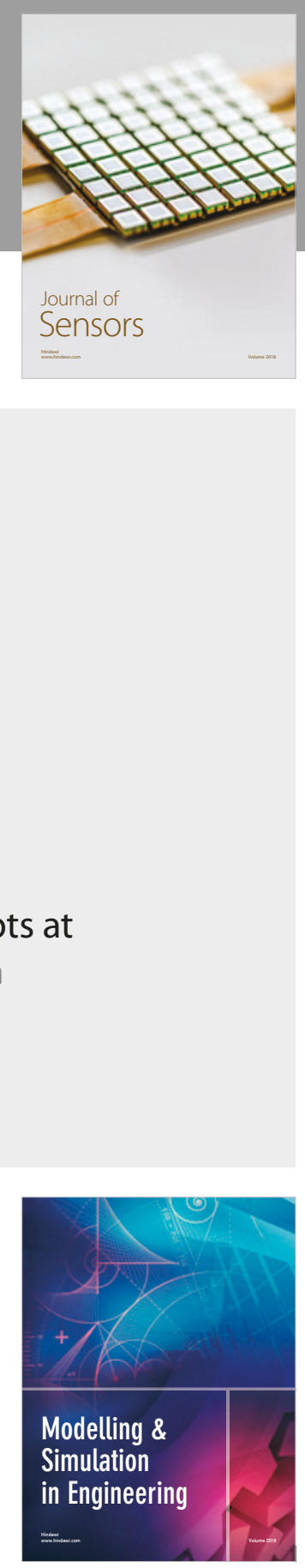

\section{Advances \\ Multimedia}
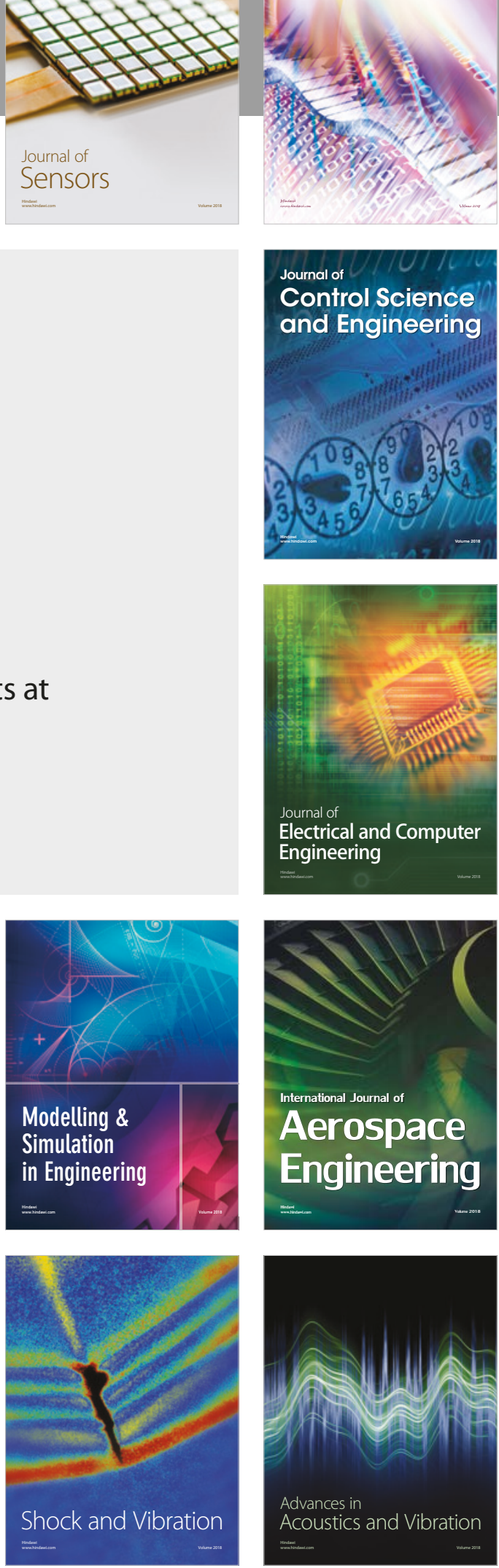